\title{
MEIOS AUTOCOMPOSITIVOS PARA O TRATAMENTO ADEQUADO DOS CONFLITOS: A EDUCAÇÃO COMO ESTRATÉGIA DE MUDANÇA SOCIOCULTURAL ${ }^{1}$
}

\author{
AUTOCOMPOSITIVE MEANS FOR THE ADEQUATE TREATMENT OF
} CONFLICTS: EDUCATION AS STRATEGY OF SOCIOCULTURAL CHANGE

Adriane Medianeira Toaldo Doutora em Direito pela UNISC. Professora do Curso de Direito da Universidade Luterana do Brasil (ULBRA). Santa Maria/RS. E-mail: adrianetoaldo@gmail.com.

Pedro Henrique da Silva Graduado em Direito Universidade Luterana do Brasil. Santa Maria/RS. E-mail: pedrohenrique130913@gmail.com

RESUMO: O presente artigo visa discutir acerca da problemática da aplicação dos meios autocompositivos para o tratamento de conflitos, em uma sociedade extremamente litigante e pautada na judicialização de seus conflitos interpessoais. Diante desta situação, propõe-se a elaboração de uma política pública capaz de implementar a solução consensual dos conflitos ainda nas séries iniciais dos ambientes escolares, de modo que seja capaz de estimular a vivência da solução consensual das controvérsias desde as primeiras interações humanas, capacitando as gerações futuras à solução adequada dos litígios pelos seus próprios meios, contribuindo para a formação de uma sociedade menos litigante e mais apta para tratar de forma adequada seus próprios conflitos, reduzindo-se o papel do Poder Judiciário àquelas situações que sejam inerentemente judiciais, tornando assim, o acesso à justiça qualificado e capaz de alcançar a ordem jurídica justa de forma tempestiva e eficaz. Para tanto, utilizando-se do método de abordagem hipotético-dedutivo e procedimento funcionalista, aborda-se ao longo do trabalho, inicialmente, o acesso à justiça, como

\footnotetext{
${ }^{1}$ Artigo recebido em 05/10/2020 e aprovado em 15/12/2020.
} 
Revista Eletrônica de Direito Processual - REDP.

Rio de Janeiro. Ano 15. Volume 22. Número 1. Janeiro a Abril de 2021

Periódico Quadrimestral da Pós-Graduação Stricto Sensu em Direito Processual da UERJ

Patrono: José Carlos Barbosa Moreira (in mem.). ISSN 1982-7636. pp. 01-28

www.redp.uerj.br

assegurado constitucionalmente, diante da atual crise que afeta o sistema judiciário, passando-se ao advento e a análise dos métodos consensuais para o tratamento dos conflitos e a resistência que a sua aplicação prática ainda acarreta, chegando-se, por fim, a conclusão pela necessidade da implementação de uma política pública capaz de estimular os indivíduos, ainda no âmbito escolar, a desenvolverem a verdadeira cultura da paz, buscando sempre pela solução dialogada e consensual dos seus conflitos.

PALAVRAS-CHAVE: Conflito. Cultura. Mediação. Conciliação. Educação.

ABSTRACT: This article aims to discuss the problem of the application of autocompositive means for the treatment of conflicts, in an extremely litigating society and based on the judicialization of their interpersonal conflicts. Given this situation, it is proposed the elaboration of a public policy capable of implementing the consensual solution of the conflicts already in the elementary school years, in order to stimulate the experience of the consensual solution of the controversies from the first human interactions, enabling future generations to adequately resolve their conflicts by their own means, contributing to the construction of a society less litigant and better able to handle its own conflicts appropriately, reducing the role of the Judiciary to the inherently judicial situations, making access to justice qualified and able to achieve a fair legal order in a timely manner it is efficient. Therefore, using the method of hypothetical-deductive approach and functionalist procedure, the article begins with the treatment of access to justice as a constitutional guarantee, in the face of the current crisis that affects the judicial system, following the advent and the analysis of the consensual methods for the handling of conflicts and the resistance that their practical application still entails, and finally concluding the need for the implementation of a public policy capable of stimulating individuals, already in the school environment, to develop a true culture of peace, always seeking a dialogical and consensual solution of their conflicts.

KEY WORDS: Conflict. Culture. Mediation. Conciliation. Education. 


\section{INTRODUÇÃO}

Em um sistema judiciário como o brasileiro, no qual a cada dia mais se torna crescente o aumento de demandas judiciais, as soluções consensuais e extrajudiciais são de extrema relevância e de importante tratamento. A judicialização está impreterivelmente atrelada a todas as áreas do direito, tendo ganho especial atenção nos últimos anos, na medida em que a sociedade está cada vez mais dinâmica e litigiosa, não comportando mais a excessiva espera por um pronunciamento judicial.

O presente trabalho se mostra extremamente pertinente e atual, pois trata acerca de uma problemática enfrentada por todos os operadores do direito e cidadãos em geral. Tanto é assim, que o atual Código de Processo Civil trouxe como uma de suas primordiais prioridades a solução consensual dos conflitos. As práticas da mediação, conciliação e outros meios autocompositivos para o tratamento dos litígios têm esbarrado em uma sociedade litigante e desacreditada da possibilidade de buscar a solução de suas contendas de forma consensual e quiçá extrajudicial.

Diante disso, explicitado se tratar de uma questão sociocultural, aborda-se como meio possível de inserir a prática das formas consensuais de tratamento dos conflitos o estímulo educacional através de uma política pública, tanto no ambiente familiar como no ambiente escolar, possibilitando a formação de uma personalidade coletiva voltada para a capacidade de tratamento adequado dos conflitos, através de métodos dialogados e consensuais para a sua consecução.

Portanto, a importância do estudo do tema está diretamente atrelada às áreas dos Direitos individuais e coletivos, bem como ao desenvolvimento humano, uma vez que a assistência jurídica e judiciária à população, além da tratativa adequada aos conflitos são questões essenciais para o desenvolvimento e aperfeiçoamento das inter-relações humanas, visando garantir a pacificação social e a convivência de forma harmônica.

O presente trabalho tem por objetivo propor a elaboração de uma política pública capaz de implementar a solução consensual dos conflitos ainda nas séries iniciais dos bancos escolares, de modo capaz a estimular a vivência da solução consensual desde as 
Revista Eletrônica de Direito Processual - REDP.

Rio de Janeiro. Ano 15. Volume 22. Número 1. Janeiro a Abril de 2021

Periódico Quadrimestral da Pós-Graduação Stricto Sensu em Direito Processual da UERJ

Patrono: José Carlos Barbosa Moreira (in mem.). ISSN 1982-7636. pp. 01-28

www.redp.uerj.br

primeiras interações humanas e capacitá-los a resolução dos litígios a ela inerentes pelos seus próprios meios, contribuindo para a formação de uma sociedade menos litigante e mais apta para tratar de forma adequada seus próprios conflitos.

Além disso, busca-se de forma mais específica demonstrar a atual crise do Sistema Judiciário Brasileiro, discorrendo inicialmente acerca da morosidade processual e o acúmulo de demandas, como consequência da excessiva judicialização dos conflitos, bem como explanar acerca dos métodos consensuais para solução de conflitos no ordenamento jurídico brasileiro, demonstrando a sua baixa efetividade diante da problemática cultural da sociedade e, por fim, discorrer sobre a necessidade de mudança cultural da sociedade frente aos métodos consensuais, demonstrando a educação como método capaz de atingir tal objetivo, através de seu estímulo desde as séries iniciais escolares.

A sociedade atual tem como principal forma de solucionar seus conflitos o Poder Judiciário, vislumbrando como única solução possível o pronunciamento judicial por meio da sentença, o que acaba tornando as partes coadjuvantes de seus próprios problemas, cedendo a sua tratativa a um terceiro, e por conseguinte, acarretando decisões que nem sempre atendem de forma satisfatória a solução do problema submetido à apreciação.

Com o advento do Código de Processo Civil, da Lei n. ${ }^{\circ}$ 13.140/2015, assim como da Resolução n. ${ }^{0}$ 125/2010 do CNJ, passou-se a um cenário de busca pela solução consensual dos conflitos como forma de garantia de acesso à ordem jurídica justa. Diante de tais aspectos, resta o questionamento de que, considerando a realidade de litigância social, bem como a busca de sua solução exclusivamente através de um pronunciamento judicial, é possível a implementação de uma política pública capaz de tornar os métodos de solução consensual dos conflitos uma cultura intrínseca a cada indivíduo?

Para tanto, utiliza-se uma metodologia de abordagem hipotético-dedutiva, uma vez que o estudo se inicia a partir da identificação da problemática do acesso à justiça e a crise do Poder Judiciário, passando-se ao falseamento da solução desta problemática através da simples normatização dos métodos autocompositivos, até se chegar a conclusão pela necessidade de uma mudança cultural através da educação.

Já o método de procedimento utilizado é o funcionalista, considerando que se procede a uma análise social, a partir da função de suas unidades, mais especificamente do Poder Judiciário, estudando-os como um sistema complexo e organizado de atividades de 
causa e efeito, relacionando diretamente o comportamento conflituoso humano com a crise que assola o sistema judiciário nacional.

A técnica de pesquisa empregada é bibliográfica, considerando que é realizada a partir de um levantamento de referências teóricas já analisadas e publicadas por meios escritos e eletrônicos, como forma de fundamentar e justificar o quanto exposto.

\section{O ACESSO À JUSTIÇA E A CRISE JURISDICIONAL BRASILEIRA}

Abordar o tema acesso à justiça é estar inevitavelmente atrelado a um direito fundamental, pois tal garantia está assegurada no art. 5. $^{\circ}$, inciso XXXV da Constituição da República, dispondo que "a lei não excluirá da apreciação do Poder Judiciário lesão ou ameaça a direito". Além disso, é um direito internacionalmente reconhecido, estabelecido na Declaração Universal dos Direitos Humanos, Convenção Americana de Direitos Humanos (Pacto de São José da Costa Rica), Convenção Europeia de Direitos Humanos, entre outros, elevando tal garantia não só como simples direito, mas como direito fundamental a todo cidadão ${ }^{2}$.

É nesse sentido que devemos entender o conceito de acesso à justiça segundo a ideia defendida por Mauro Capelletti e Bryant $\mathrm{Garth}^{3}$, os quais classificam este direito fundamental atrelando-o ao binômio possibilidade/viabilidade, buscando à igualdade de condições para se acessar o sistema judiciário, e por consequência buscar um provimento jurisdicional ao direito ou interesse que entende estar ameaçado, com o intuito de tentar alcançar a produção de resultado justo e efetivo.

O sistema judiciário brasileiro enfrenta uma grave crise na sua própria essência, encontrando-se altamente saturado em razão do número elevado de demandas que são ajuizadas incessantemente, não dando conta de resolver de forma minimamente satisfatória e tempestiva os conflitos que são levados a sua apreciação.

\footnotetext{
2 BRASIL. Constituição da República Federativa do Brasil. Brasília, DF: 1988. Disponível em: http://www.planalto.gov.br/ccivil_03/constituicao/constituicao.htm. Acesso em: 22 mai.2019.

${ }^{3}$ CAPPELLETTI, Mauro; GARTH, Bryant. Acesso à justiça. Porto Alegre: Safe, 1988.
} 
Segundo o Conselho Nacional de Justiça, no ano de 2017 existiam 80,1 milhões de processos aguardando julgamento no Brasil, sendo que, destes, 94\% encontravam-se tramitando no primeiro grau de jurisdição, e disso tudo $84 \%$ foram ajuizados somente dentro dos três anos anteriores ${ }^{4}$.

Existem diversos fatores que podem explicar esta crise, tais como o baixo número de servidores, a falta de investimentos, a precariedade das estruturas como um todo, dentre inúmeros outros. Todos estes são motivos plausíveis e, não justificam, mas explicam o cenário caótico do Poder Judiciário nacional. Todavia, o mais importante deles não é de ordem material, pois encontra-se inserido dentro da personalidade social de cada indivíduo, qual seja, a própria litigiosidade, esboçada no demandismo judicial.

As políticas públicas adotadas nos últimos anos insistem no vezo de atacar diretamente o efeito desta crise, ou seja, a sobrecarga de processos, excogitando-se e positivando-se medidas de toda ordem, que não raras vezes acabam por suprimir garantias do próprio devido processo legal, deixando de lado os reais motivos que estão na base de todo o contexto, comparando-se a atitude de um médico que insiste em baixar a febre do paciente sem investigar as reais causas da moléstia ${ }^{5}$.

Não se está a falar em vedação do acesso à justiça em hipótese alguma, tanto é assim que o legislador constituinte o elencou no rol de direitos fundamentais. $\mathrm{O}$ que se torna necessário, ante a atual crise jurisdicional, é garantir não somente o mero acesso à justiça, mas sim o acesso à ordem jurídica justa, como verdadeira consecução de um direito fundamental.

Para Luiz Guilherme Marinoni ${ }^{6}$, a preocupação com o acesso à justiça não deve levar à litigância, porquanto não se pode confundir este direito com facilidade de litigar. $\mathrm{O}$ ajuizamento de uma ação implica em consequências de natureza pessoal e econômica, devendo ser efetivada sempre mediante a análise dos benefícios e prejuízos que a sua propositura poderá acarretar.

\footnotetext{
4 BRASIL. Conselho Nacional de Justiça. Justiça em números. Disponível em: http://www.cnj.jus.br/files/conteudo/arquivo/2018/09/da64a36ddee693ddf735b9ec03319e84.pdf. Acesso em: 14 mai.2019.

${ }^{5}$ MANCUSO, Rodolfo de Camargo. Acesso à justiça: condicionantes legítimas e ilegítimas. São Paulo: Revista dos Tribunais, 2011.

${ }^{6}$ MARINONI, Luiz Guilherme. Política pública do Poder Judiciário nacional para tratamento adequado dos conflitos de interesses. Revista de Processo, São Paulo, n. 195, mai. 2011.
} 
Revista Eletrônica de Direito Processual - REDP.

Rio de Janeiro. Ano 15. Volume 22. Número 1. Janeiro a Abril de 2021

Periódico Quadrimestral da Pós-Graduação Stricto Sensu em Direito Processual da UERJ

Patrono: José Carlos Barbosa Moreira (in mem.). ISSN 1982-7636. pp. 01-28

www.redp.uerj.br

Por outro lado, Kazuo Watanabe ${ }^{7}$ assevera que o acesso à justiça não é a mera provocação do Poder Judiciário mediante $\mathrm{o}$ ajuizamento do processo, mas fundamentalmente o direito de acesso à ordem jurídica justa, que somente pode ser alcançado na presença de elementos considerados por ele indispensáveis, como o direito à informação, a adequação entre a ordem jurídica e a realidade econômica do país, o direito a uma justiça adequadamente organizada e formada por juízes inseridos na realidade social e comprometidos com o objetivo e realização da ordem jurídica justa, direito a préordenação dos instrumentos processuais capazes de promover a efetiva tutela de direitos e a garantia à remoção de todos os obstáculos que se anteponham ao acesso.

Garantir o mero acesso à justiça sem que haja um planejamento para atendimento e resolução destas demandas sociais, inegavelmente acarreta uma excessiva sobrecarga de serviços, sem que se tenha um mínimo de atendimento satisfatório aos litígios submetidos à apreciação, fazendo com que, por óbvio, reste sobrecarregado este sistema.

A litigiosidade é algo que está intrínseco em cada indivíduo, cabendo a cada um conseguir controlá-la da melhor maneira possível. E isto é facilmente notado em qualquer época da evolução humana que se pretender analisar, desde as mais primitivas até as mais atuais, somente se alterando com o passar dos anos os objetos destes litígios e, logicamente as regras, mandamentos, leis, etc., aplicáveis aos casos.

No transcorrer dos anos, com o advento das novas tecnologias e, consequentemente maior abrangência das informações, os conflitos interpessoais passaram a se tornar cada vez mais complexos e intensos, ao mesmo passo em que a população passou a tomar conhecimento de seus direitos de forma mais rápida e simplificada, buscando cada vez mais o acesso à justiça, no intuito de ter as suas garantias atendidas.

Contudo, o Poder Público, mais precisamente o Poder Judiciário, não acompanhou esta evolução, pois assegurou à população somente a possibilidade de acessá-lo formalmente, como não poderia deixar de ser, mas não a de obter o resultado desejado para o tratamento adequado do conflito e em tempo minimamente razoável, o verdadeiro acesso à justiça.

\footnotetext{
${ }^{7}$ WATANABE, Kazuo. Acesso à justiça e sociedade moderna: participação e processo. São Paulo: Revista dos Tribunais, 1988
} 
O motivo da baixa eficácia das decisões encontra-se indissociavelmente ligado a própria natureza do processo judicial, na medida em que a decisão final é efetivada por um terceiro estranho às partes e, portanto, sem conhecimento das especificidades que orbitam em cada conflito, o que, aliado à morosidade para se chegar até estas decisões, considerando o número invencível de demandas, acabam por não atenderem aos anseios sociais de forma satisfatória, causando, por vezes, severo descontentamento e clamor social.

No entender de Mauro Vasni Paroski ${ }^{8}$, o que põe em risco o acesso à justiça e compromete a efetividade e eficiência das instituições não é a demora razoável, considerada aquela necessária para a garantia do devido processo legal, mas, sim, o excesso de tempo que existe na grande maioria dos processos em tramitação.

A atual crise do judiciário, vez que a busca excessiva pela judicialização acaba por ocasionar um número estarrecedor de ações judiciais por Comarcas. Resta nítida a necessidade de maior incentivo a formas alternativas de solução consensual dos litígios, tanto em sede judicial como, principalmente, extrajudicial.

Nesse sentido, passaram a se destacar os meios consensuais para tratamento dos conflitos, que adotam um viés social intimamente ligado com a própria realização da Justiça, especialmente em razão do excessivo número de conflitos judicializados? ${ }^{9}$.

Outro fato que merece destaque no presente estudo e que está diretamente ligado ao crescente número de processos judiciais é a crença comum de que a resolução dos conflitos somente se dá por meio de decisão judicial, por uma sentença proferida pelo Juiz. Nesta esteira, as partes deixam de ser protagonistas de seus próprios problemas e depositam única e exclusivamente a expectativa de sua "resolução" a um terceiro totalmente estranho à lide.

No entender de Rodolfo de Camargo Mancuso ${ }^{10}$, a busca pela solução suasória dos conflitos é capaz de estimular a própria e verdadeira cidadania, buscando o tratamento da controvérsia entre os próprios interessados, não entregando ao Estado-juiz a obrigação de

\footnotetext{
${ }^{8}$ PAROSKI, Mauro Vasni. Direitos fundamentais e acesso à justiça na Constituição. São Paulo: LTr, 2008.

${ }^{9}$ TARTUCE, Fernanda; SILVA, Erica Barbosa. A conciliação diante da política judiciária de tratamento adequado de conflitos. In TUCCI, José Rogério Cruz; RODRIGUES, Walter Piva; AMADEO, Rodolfo da Costa Manso Real (Coord.). Processo civil: homenagem a José Ignacio Botelho De Mesquita. São Paulo: Quartier Latin, 2013.

${ }^{10}$ MANCUSO, Rodolfo de Camargo. Acesso à justiça: condicionantes legítimas e ilegítimas. São Paulo: Revista dos Tribunais, 2011.
} 
todo e qualquer conflito. Prossegue ao afirmar que a cultura demandista caracteriza um falso exercício da cidadania, promovendo o acirramento dos desentendimentos, o afastamento das partes, bem como, estendendo o conflito a um ponto futuro e indefinido, prejudicando as relações sociais e sobrecarregando o Estado com problemas que poderiam e deveriam resolver-se de modo auto ou heterocompositivo.

De acordo com Kazuo Watanabe ${ }^{11}$, o mecanismo utilizado pelo sistema judiciário é o da solução adjudicada dos conflitos, o qual se dá através de uma sentença judicial proferida pelo juiz. E é a predominância desse critério que criou a chamada "cultura da sentença", gerando consequentemente o aumento de recursos e execuções, explicando não só o congestionamento processual nas instâncias ordinárias, como também nos Tribunais Superiores.

Assim, as partes deixam de lado a sua capacidade de dialogar e pôr em prática possibilidades menos desgastantes, mais ágeis, efetivas e consensuais de solucionar os conflitos, tendo em mente o conceito errôneo de que o Poder Público irá solucionar o seu problema. Tal ideal, na prática, somente acarreta mais gastos, mais demora e menos eficácia, afinal, a sociedade precisa identificar e compreender que não há ninguém melhor para solucionar e tratar os seus litígios do que os próprios interessados, tendo em vista que somente eles têm o conhecimento e a capacidade de saber o que será o melhor para cada um, pois o juiz somente aplicará a lei ao caso concreto.

Nesse contexto, é preciso dar especial atenção aos métodos consensuais de solução de conflitos, principalmente pelo fato de que valorizam o diálogo entre as partes para se chegar consensualmente ao fim do conflito gerado e o restabelecimento do convívio entre os envolvidos, de forma muito mais ágil e eficaz do que o sistema judiciário tradicional.

\section{OS MÉTOdOS CONSENSUAIS PARA A SOLUÇÃO DE CONFLITOS NO ORDENAMENTO JURÍDICO BRASILEIRO}

O conflito, por si só, não deve ser entendido como algo prejudicial dentro das relações humanas, na medida em que constitui verdadeiro instrumento para a garantia da

\footnotetext{
${ }^{11}$ WATANABe, Kazuo. Política pública do Poder Judiciário nacional para tratamento adequado dos conflitos de interesses. [S.1.]: Virtual Books, 2011. Disponível em: http://www.tjsp.jus.br. Acesso em: 23 mai.2019.
} 
Revista Eletrônica de Direito Processual - REDP.

Rio de Janeiro. Ano 15. Volume 22. Número 1. Janeiro a Abril de 2021

Periódico Quadrimestral da Pós-Graduação Stricto Sensu em Direito Processual da UERJ

Patrono: José Carlos Barbosa Moreira (in mem.). ISSN 1982-7636. pp. 01-28

www.redp.uerj.br

evolução social, permitindo o amoldamento de condutas, regras, padrões, culturas, instrumentos, e tudo mais que se possa imaginar, de acordo com as aspirações do cotidiano, promovendo a dinamicidade do tecido social, afinal, uma sociedade sem conflitos é estática.

Para Clóvis Gorczevski ${ }^{12}$, o conflito é o propulsor do desenvolvimento humano, podendo-se permanecer dentro da normalidade ou transformar-se em algo prejudicial, o que depende exclusivamente do tratamento que se dará a ele. Será negativo sempre que chegar a uma confrontação hostil ou violenta, mas será positivo quando for possível controlá-lo e canalizá-lo no sentido de compreender e aceitar diferenças.

Ocorre que, aliado ao conflito, está a própria litigiosidade, inerente ao instinto natural da raça humana, herança de nossos ancestrais, que primavam pelo tratamento das controvérsias através da violência, sem antes mesmo tentar qualquer diálogo efetivo. A primazia para o tratamento litigioso dos conflitos persiste, só que agora, principalmente utilizando-se do Poder Judiciário.

É preciso compreender que o Direito não resolve conflitos, ao menos não aquele real que efetivamente gerou o conflito externo, aquele que é íntimo e pessoal. Em juízo, aplica-se a técnica da substituição, o conflito passa a ser meramente jurídico, pertencente ao próprio Estado e não mais aos interessados, deixando de ser pessoal para se tornar “juridicamente interpretável e juridicamente decidível"13. A decisão judicial resolve exclusivamente aquele conflito jurídico, criado pelo próprio Estado, mas jamais resolverá o conflito das partes.

Por tudo isso, tornou-se evidente a necessidade de se implementar políticas efetivas para o tratamento adequado dos conflitos, visando a autocomposição, seja ela judicial ou extrajudicial. Nesse contexto é que se deram largos passos com o advento dos novéis diplomas legais dos últimos anos, que visam a implementação de meios autocompositivos para o tratamento adequado dos conflitos de interesses, dentre os quais podemos destacar a Lei n. ${ }^{\circ}$ 13.140, de 26 de junho de 2015 - denominada de Marco Legal da Mediação, a Lei n. ${ }^{\circ}$ 13.105, de 16 de março de 2015 - Código de Processo Civil, a Resolução n. ${ }^{\circ}$ 125, do

\footnotetext{
12 GORCZEVSKI, Clóvis. Jurisdição paraestatal: solução de conflitos com respeito à cidadania e aos direitos humanos na sociedade cultural. Porto Alegre: Imprensa Livre, 2007.

${ }^{13}$ GORCZEVSKI, Clóvis. Jurisdição paraestatal: solução de conflitos com respeito à cidadania e aos direitos humanos na sociedade cultural. Porto Alegre: Imprensa Livre, 2007. p. 40.
} 
Revista Eletrônica de Direito Processual - REDP.

Rio de Janeiro. Ano 15. Volume 22. Número 1. Janeiro a Abril de 2021

Periódico Quadrimestral da Pós-Graduação Stricto Sensu em Direito Processual da UERJ

Patrono: José Carlos Barbosa Moreira (in mem.). ISSN 1982-7636. pp. 01-28

www.redp.uerj.br

Conselho Nacional de Justiça, de 29 de novembro de 2010, além da própria Lei da Arbitragem, Lei n. ${ }^{\circ}$ 9.307, de 23 de setembro de 1996.

Dentre os principais métodos suasórios de tratamento dos conflitos, destacam-se a mediação, a conciliação e a arbitragem, como os mais utilizados e efetivos para esta finalidade.

A mediação é um procedimento no qual um terceiro neutro e estranho às partes facilita a restauração do diálogo rompido em razão do conflito, com o objetivo de se chegar a sua verdadeira resolução. O mediador não propõe acordos, mas tão somente estimula o contato para que os envolvidos, por si próprios, cheguem a um consenso. Justamente por este motivo que a mediação é recomendada e comumente utilizada quando as partes já possuem um relacionamento prévio, pois a finalidade é restabelecê-lo, podendo ser utilizada tanto judicial como extrajudicialmente.

Já a conciliação é um procedimento conduzido por um terceiro que se restringe aos aspectos objetivos e materiais do conflito, auxiliando e conduzindo as partes para que cheguem a solução do litígio. A conciliação é empregada quando não há qualquer relacionamento anterior entre os conflitantes, motivo pelo qual o conciliador dialoga juntamente com as partes para se chegar ao acordo, fazendo propostas e delineando os termos da avença. Assim como a mediação, pode ocorrer dentro do processo judicial, como também pode ser utilizada de forma pré-processual.

A arbitragem, por sua vez, é fruto direto da autonomia de vontade dos conflitantes, que consensualmente decidem submeter o litígio à apreciação de um terceiro por eles escolhidos, o árbitro, que diferentemente dos institutos antes citados, normalmente será uma pessoa com conhecimentos técnicos sobre o assunto objeto da lide. Entretanto, o único requisito estabelecido pela Lei n. ${ }^{\circ}$ 9.307/1996 é que o árbitro deve ser uma "pessoa capaz e que tenha a confiança das partes"14.

O juízo arbitral funciona da mesma forma que o juízo comum estatal, mediante a instauração de um expediente específico, no qual devem ser garantidos os princípios primordiais do contraditório e da ampla defesa, sendo a sentença arbitral de cumprimento

\footnotetext{
${ }^{14}$ BRASIL. Manual de mediação judicial do Conselho Nacional de Justiça. Brasília: 2016. Disponível em: http://www.cnj.jus.br/files/conteudo/arquivo/2016/07/f247f5ce60df2774c59d6e2dddbfec54.pdf. Acesso em: 13 de mai.2019.
} 
obrigatório pelas partes, inclusive constituindo título executivo judicial, nos termos do art. 515, inciso VII, do Código de Processo Civil.

No entendimento de Luiz Alberto Warat ${ }^{15}$, os métodos consensuais, uma vez entendidos como práticas de pacificação social, situam-se externamente a qualquer demanda formalizada perante o Poder Judiciário ou Juízo Arbitral, analisando-as de forma genérica e abstrata, enquanto técnicas apropriadas à sociedade para identificar diferenças e superar divergências.

A utilização dos métodos consensuais de tratamento dos conflitos alcança benefícios tanto de ordem material como imaterial, na medida em que não só contribui para o descongestionamento do Poder Judiciário, resolução tempestiva e adequada dos conflitos, efetividade das decisões/avenças, como também proporcionam o restabelecimento do convívio social, promovendo efetivamente o tratamento do litígio.

Neste passo, restou claro o objetivo do legislador em efetivar tais métodos, tanto dentro do processo judicial, com o objetivo de promover a possibilidade da composição do litígio entre as partes e, consequentemente, por fim as demandas, visando a celeridade e resolução da lide, como extrajudicial, a fim de evitar a judicialização do conflito, viabilizando o consenso sem a necessidade da propositura de ações judiciais.

A primeira regulamentação neste sentido ocorreu com a edição da Lei n. ${ }^{\circ}$ 9.307, de 23 de setembro de 1996, que instituiu a Lei da Arbitragem, criando e regulamentando a aplicação deste instituto. No entanto, o juízo arbitral acabou sempre mitigado frente a “justiça oficial estatal”, razão pela qual até hoje possui uma aplicabilidade reduzida.

Contudo, foi somente no ano de 2010 com a criação da Resolução n. ${ }^{\circ} 125$, de 29 de novembro de 2010 do CNJ, que foi instituída a "Política Judiciária Nacional de tratamento dos conflitos de interesses, tendente a assegurar a todos o direito à solução dos conflitos por meios adequados à sua natureza e peculiaridade", regulando, ainda que por um ato administrativo, as disposições básicas necessárias para viabilizar de fato a aplicação dos métodos consensuais, especialmente a mediação e a conciliação ${ }^{16}$.

\footnotetext{
15 WARAT, Luis Alberto. A mediação. 1999. Disponível em: http://www.almed.org.br. Acesso em: 29 mai.2018.

16 BRASIL. Conselho Nacional de Justiça. Resolução n. 125, de 29 de novembro de 2010. Política Judiciária Nacional de tratamento adequado dos conflitos de interesses no âmbito do Poder Judiciário. Brasília: Conselho Nacional de Justiça, 2010. Disponível em: http://www.cnj.jus.br/busca-atosadm?documento=2579. Acesso em: 29 abr.2019.
} 
Revista Eletrônica de Direito Processual - REDP.

Rio de Janeiro. Ano 15. Volume 22. Número 1. Janeiro a Abril de 2021

Periódico Quadrimestral da Pós-Graduação Stricto Sensu em Direito Processual da UERJ

Patrono: José Carlos Barbosa Moreira (in mem.). ISSN 1982-7636. pp. 01-28

www.redp.uerj.br

Cinco anos mais tarde, o Código de Processo Civil estabeleceu no art. $3 .^{\circ}, \S 33^{\circ}$, dentre as suas normas fundamentais, que "a conciliação, a mediação e outros métodos de solução consensual de conflitos deverão ser estimulados por juízes, advogados, defensores públicos e membros do Ministério Público, inclusive no curso do processo judicial”. Além disso, elevou o papel dos profissionais que atuam nesta área, conciliadores e mediadores, a posição de auxiliares da justiça, regulamentando o assunto a partir do art. 165 e seguintes $^{17}$.

Quase que contemporaneamente ao diploma processual, foi editada a Lei n. $^{\circ}$ 13.140, de 26 de junho de 2015, denominada como Marco Legal da Mediação, dispondo "sobre a mediação entre particulares como meio de solução de controvérsias e sobre a autocomposição de conflitos no âmbito da administração pública", regulando ainda questões pontuais ao exercício das práticas conciliatórias, como a habilitação e qualificação dos profissionais, as formas de realizações das sessões judicial e extrajudicialmente, entre outras ${ }^{18}$.

Com a implementação dos métodos consensuais em termos judiciais, se tem um reconhecido avanço na diminuição dos processos judiciais, permitindo o melhor atendimento dos casos postos à apreciação através de sua resolução de forma dialogada, tornando as próprias partes protagonistas do conflito, deixando de lado a necessidade de um terceiro estranho a elas e aos fatos decidir, atendendo de forma mais precisa o conflito, pois somente as partes têm conhecimento daquilo que melhor atende e se adequa aos seus interesses, contribuindo ainda para a diminuição de demandas do Poder Judiciário.

Nesse sentido, ao falar sobre a mediação Luis Alberto Warat ${ }^{19}$ ensina que a mediação possui um valor pedagógico, na medida em que proporciona autonomia e protagonismo às partes do conflito, conferindo um valor democrático ao possibilitar que as

\footnotetext{
${ }^{17}$ BRASIL. Lei n. ${ }^{0}$ 13.140, de 26 de junho de 2015: dispõe sobre a mediação entre particulares como meio de solução de controvérsias e sobre a autocomposição de conflitos no âmbito da administração pública; altera a Lei $\mathrm{n}^{\circ} 9.469$, de 10 de julho de 1997 , e o Decreto $\mathrm{n}^{\circ} 70.235$, de 6 de março de 1972; e revoga o $§ 2^{\circ}$ do art. $6^{\circ}$ da Lei $\mathrm{n}^{\circ}$ 9.469, de 10 de julho de 1997. Brasília: Senado Federal, 2015. Disponível em: http://www.planalto.gov.br/ccivil_03/_Ato2015-2018/2015/Lei/L13140.htm. Acesso em: 15 abr.2019.

18 BRASIL. Lei n. 13.105, de 16 de março de 2015: Código de Processo Civil. Brasília: Senado Federal, 2015. Disponível em: http://www.planalto.gov.br/ccivil_03/_Ato2015-2018/2015/Lei/L13105.htm. Acesso em: 29 mar.2019.

${ }^{19}$ WARAT, Luis Alberto. A mediação. 1999. Disponível em: http://www.almed.org.br. Acesso em: 29 mai.2018.
} 
pessoas decidam por elas mesmas, gerando empoderamento e reconhecimento de suas capacidades enquanto decisores.

Nos conflitos extrajudiciais as práticas consensuais mostram-se ainda mais eficazes quando utilizadas, vez que permitem o tratamento imediato e eficaz ao conflito em questão, não necessitando de sua submissão a um pronunciamento jurisidicional, o que possibilita o atendimento dos conflitos de forma mais célere e em melhores condições, de uma maneira praticamente instantânea, pois somente dependeria da vontade dos próprios interessados.

Os métodos autocompositivos tornam-se uma forma de "restaurar a comunicação rompida entre as partes em virtude da posição antagônica instituída pelo litígio"20 , através do qual a sua principal dificuldade é encontrar formas que possibilitem uma convivência pacífica. Por isso, é que se vale da teoria habermasiana para, por meio da busca pela racionalidade, gerar o consenso e atuar como verdadeira estratégia política, incluindo o papel das subjetividades para renovação da sociedade.

Reforça-se que a mediação, a conciliação ou qualquer dos outros métodos suasórios de tratamento dos conflitos, sejam públicos ou coletivos, judiciais ou extrajudiciais, proporcionam primordialmente às partes que sejam os protagonistas na solução dos seus próprios conflitos, delineando pelos seus próprios meios as melhores condições para se chegar à composição da lide, podendo levar em conta todas as circunstâncias que permeiam o desentendimento, e verdadeiramente restabelecer o status quo ante, deixando a adjudicação do conflito ao Estado-juiz em caráter subsidiário.

Neste passo, a mais eficiente disponibilização dos “equivalentes jurisdicionais" está no fortalecimento da verdadeira cidadania, que consiste em estimular as partes a comporem o conflito entre si ou com o auxílio de terceira pessoa, a fim de deslocar a via judicial a um plano subsidiário ou residual, restringindo-se a sua utilização nos conflitos não resolvidos de forma alternativa, em razão de sua peculiaridade material ou pessoal, bem como àqueles que envolvem crise jurídica relevante ${ }^{21}$.

\footnotetext{
${ }^{20}$ SPENGLER, Fabiana Marion. Da jurisdição à mediação: por uma outra cultura no tratamento dos conflitos. Ijuí: Unijuí, 2010. p. 349,

${ }^{21}$ MANCUSO, Rodolfo de Camargo. Acesso à justiça: condicionantes legítimas e ilegítimas. São Paulo: Revista dos Tribunais, 2011.
} 
Com tais métodos, o que se verifica é uma maior valorização das partes, enquanto protagonistas e geradoras do conflito a ser solucionado, mantendo o controle sobre ele, identificando as questões que estão envolvidas e encontrando os métodos para desenvolvê$\operatorname{las}^{22}$.

No entanto, esta prática encontra-se obstacularizada por diversos fatores da atual conjuntura, não estando a disposição dos litigantes da forma como desejada, operando fora da capacidade que deveria se considerado o seu alto potencial, o que se dá, dentre outras causas, e em um primeiro momento, pela falta de organização física e procedimental deste método, tendo em vista que todos os dispositivos legais já citados embora disciplinem a matéria, não foram capazes de introduzi-la definitivamente no meio social.

Mauro Vasni Paroski ${ }^{23}$, ao falar sobre o assunto, adverte que nada se resolve com a simples instituição formal de direitos e garantias, caso não sejam efetivados no plano fático, tornando-os efetivos, sendo necessário que, para tanto, os seus efeitos sejam passíveis de serem sentidos pelos seus destinatários.

Ainda que se tenha dado um importante passo com a implementação, estimulação e regulamentação da autocomposição no ordenamento jurídico brasileiro, percebe-se ainda certo menosprezo quanto a aplicação destes métodos não só pelas partes, mas pelos próprios operadores do direito, legisladores, administradores, etc. Aparentemente, nem mesmo estes sujeitos acreditam nas capacidades que os métodos consensuais possuem, o que se evidencia de forma exemplificativa no fato de nomeá-los como "métodos alternativos", denotando a impressão de ser o Poder Judiciário o "padrão oficial” para a resolução de conflitos.

Sob este aspecto, afirma José Renato Nalini ${ }^{24}$ que é saudável ao Poder Judiciário que haja um leque para a solucionar o conflito, sendo a melhor postura para o Magistrado admitir que pode conviver com estas alternativas, sem perder a sua condição de caráter subsidiário, devendo assumir uma postura coordenadora dos novos métodos, aludindo que seria uma alternativa para a salvação dos questionados métodos convencionais de tratamento dos conflitos.

\footnotetext{
${ }^{22}$ PAROSKI, Mauro Vasni. Direitos fundamentais e acesso à justiça na Constituição. São Paulo: LTr, 2008.

${ }^{23}$ PAROSKI, Mauro Vasni. Direitos fundamentais e acesso à justiça na Constituição. São Paulo: LTr, 2008.

${ }^{24}$ NALINI, José Renato. A rebelião da toga. Campinas: Millenium, 2006.
} 
Por isso, torna-se necessário um maior incentivo aos métodos consensuais pelo Poder Público, através de uma política pública apta e eficaz para alterar este quadro, de modo que os próprios envolvidos aprendam a tratá-la com a seriedade e confiança que merece, tendo em vista que a prática da conciliação, mediação e demais métodos, são capazes de elevar as partes como protagonistas do seu próprio litígio, sendo forma capaz de adjudicar a chamada "cultura da sentença".

Jurgen Habermas ${ }^{25}$, em sua Teoria da Ação Comunicativa, assevera que o entendimento deve ser buscado através do diálogo, especialmente para que o Direito seja utilizado como forma para a socialização e emancipação, tanto individual como coletiva, através da interação e do entendimento entre os membros da comunidade, evitando-se o prevalecimento das ações instrumentais nas relações humanas.

$\mathrm{Na}$ mesma esteira, em que pese todos os pontos positivos que as práticas consensuais trazem a qualquer litígio a que forem empregadas, já enunciados anteriormente, o obstáculo mais dificultoso para a sua implementação reside no descrédito das partes em sua aplicação.

Tal situação é decorrente de uma série de fatores socioculturais que se encontram enraizados na personalidade de cada indivíduo, percebendo-se uma constante busca pela vantagem absoluta nas demandas, uma razão absoluta, de modo que cada parte, guardadas as suas proporções, entende que somente ela tem razão no litígio e, portanto, não deve transigir e ceder em relação ao seu direito, porque acredita e busca o máximo.

De acordo com o Manual de Mediação Judicial do Conselho Nacional de Justiça, tal prática é denominada como "negociação posicional", a qual consiste no fato das partes se tratarem como oponentes, implicando pensar na negociação em termos de somente uma ganhar e outra perder ${ }^{26}$.

Citando novamente o brilhante doutrinador Luís Alberto Warat ${ }^{27}$, falando especificamente sobre a mediação, ensina que os conflitos são carregados de inúmeros sentimentos, que atrapalham na sua tranquila resolução. Neste ponto, as práticas da mediação envolvem a transformação dos sentimentos das partes envolvidas no conflito,

\footnotetext{
${ }^{25}$ HABERMAS, Jurgen. Teoria de la acción comunicativa, I: racionalidad de La acción y racionalización social. Madrid: Taurus, 1987.

${ }^{26}$ BRASIL. Manual de mediação judicial do Conselho Nacional de Justiça. Brasília, 2016.

${ }^{27}$ WARAT, Luis Alberto. O ofício do mediador. Florianópolis: Habitus, 2001.
} 
proporcionando a observação do conflito interior de cada envolvido. Ainda, são as próprias partes que em conjunto encontram soluções que sejam para ambas satisfatórias, com a ajuda do mediador.

Ainda sobre o tema, Rodolfo de Camargo Mancuso ${ }^{28}$ alude que a satisfação efetiva dos interesses das partes pode se dar de forma mais intensa quando é por elas criada, e não imposta pelo juiz. Assim, há vários fatores que não recomendam ou tornam pouco atraente a submissão do conflito à justiça estatal, que se dá exclusivamente através de uma solução adjudicada, acirrando os ânimos e distanciando os interessados, "polarizando-os na dicotomia 'vencedor-vencido"'. Ainda, estende a resolução do litígio a um ponto futuro e indefinido, traz insegurança às partes, tendo em vista a dispersão jurisprudencial, pouca eficácia nos comandos condenatórios e prestacionais registrando pouca eficácia prática, seja pelo decurso do tempo do processo de conhecimento ou pela forte oposição do vencido na fase de execução.

Por tudo isso, torna-se imprescindível a promoção de uma estratégia capaz de despertar tanto nas partes como nos operadores jurídicos a cultura pela paz, fomentando e acreditando no tratamento adequado dos conflitos de forma consensual primordialmente, deixando-se para trás a ideia de adjudicação do litígio ao Poder Judiciário.

Por isso é que se mostra necessária a implementação de uma política pública de viés educacional, voltada para a promoção dos métodos consensuais ainda nas séries iniciais escolares, com o objetivo de proporcionar uma verdadeira mudança sociocultural.

\section{A EDUCAÇÃO COMO INSTRUMENTO CAPAZ DE PROMOVER A CULTURA DA PAZ}

Não obstante os novos métodos consensuais para tratamento dos conflitos trazidos pelas novas legislações, ainda se observa uma grande demanda de judicialização dos litígios na sociedade. As normativas e tentativas de implementação dos métodos autocompositivos, como a mediação, a conciliação e a arbitragem, não foram suficientes para a redução no número de processos judiciais, que somente aumentaram nos últimos

\footnotetext{
${ }^{28}$ MANCUSO, Rodolfo de Camargo. Acesso à justiça: condicionantes legítimas e ilegítimas. São Paulo: Revista dos Tribunais, 2011.
} 
anos, o que vem corroborado pela morosidade processual e o demandismo judicial. Então, por que os métodos autocompositivos de resolução de conflitos ainda não começaram a fazer efeitos?

Ora, fica claro que tal pergunta é extremamente pertinente e condiz com a realidade do atual cenário judicial em que nos encontramos. Nesse sentido, é extremamente difícil de explicar os motivos pelos quais uma política pública que já está idealizada e ao menos positivada há mais de oito anos, desde o advento da Resolução n. ${ }^{\circ} 125$ do CNJ, ainda não está completamente implementada e surtindo os efeitos que deveria.

Com efeito, há dois motivos completamente distintos e capazes de explicar melhor esta questão. Primeiro, destaca-se a falta de investimentos e a demora na efetivação e regulamentação dos métodos consensuais, os quais caminham em passos curtos, tendo em vista que após a Resolução n. ${ }^{\circ}$ 125/2010, os institutos somente foram ser novamente regulamentados e efetivamente implementados no ano de 2015, através do Código de Processo Civil (Lei n. ${ }^{\circ}$ 13.105/15) e da Lei da Mediação (Lei n. ${ }^{\circ}$ 13.140/15), ainda assim pairando muitas indefinições e sendo empregado de forma tímida se comparado ao alcance que pode atingir.

Fernanda Tartuce ${ }^{29}$, ao comentar sobre o Marco Legal da Mediação, afirma que, por longo período, a falta de regulamentação para a mediação trouxe preocupações para o meio jurídico. Por um lado, podia-se pensar que a mediação, por ser fundamentalmente baseada na informalidade poderia ser desempenhada melhor sem "amarras legais", por outro, a falta de previsões gerou insegurança em relação a sua aplicabilidade, em especial na forma extrajudicial, com a contratação de serviços privados, acreditando-se que este fator limitou a utilização do instituto.

Nesse sentido, ainda que os métodos autocompositivos sempre tenham existido, a sua aplicação em período anterior à Resolução do Conselho Nacional de Justiça era extremamente escassa, pontual e completamente desregrada. Somente no ano de 2010 que veio a surgir a primeira regulamentação destes institutos no ordenamento jurídico brasileiro.

\footnotetext{
${ }^{29}$ TARTUCE, Fernanda. O novo marco legal da mediação no direito brasileiro. 2016. Disponível em: http://www.fernandatartuce.com.br/wp-content/uploads/2017/01/O-novo-marco-legal-da-mediacao-nodireito-brasileiro-2016-Fernanda-Tartuce.pdf. Acesso em: 18 mai.2019.
} 
Revista Eletrônica de Direito Processual - REDP.

Rio de Janeiro. Ano 15. Volume 22. Número 1. Janeiro a Abril de 2021

Periódico Quadrimestral da Pós-Graduação Stricto Sensu em Direito Processual da UERJ

Patrono: José Carlos Barbosa Moreira (in mem.). ISSN 1982-7636. pp. 01-28

www.redp.uerj.br

Entretanto, em que pese o espírito trazido pelo texto da Resolução, incentivando os métodos conciliatórios, regulamentando alguns procedimentos e, o mais importante, determinando que os Tribunais de Justiça do país providenciassem no âmbito de suas competências a criação de núcleos para o desenvolvimento da autocomposição dos conflitos, na prática, esta realidade demorou a se concretizar, na medida em que a normativa criada não produziu o efeito imediato que desejava, somente alcançando uma maior abrangência e efetividade após a regulamentação por lei federal, e a sua previsão no Código de Processo Civil, ambas somente cinco anos mais tarde.

Contudo, ainda hoje existem estados brasileiros que não dispõem de Centros Judiciários de Solução de Conflitos e Cidadania - CEJUSC's, o que somente reforça o sentimento de descrédito das instituições oficiais para com os métodos consensuais, porquanto ainda que se entendam as dificuldades financeiras que os estados da federação vêm sofrendo, o que afeta diretamente também o Poder Judiciário, é necessário que diante de tamanha crise na existência do sistema judicial, este assunto adquira especial atenção, inclusive financeira, afinal poderia desonerar os demais setores.

Para José Luiz Bolzan de Morais e Fabiana Marion Spengler ${ }^{30}$, a resistência quanto a utilização dos métodos consensuais tem sido alvo de críticas pelos operadores do direito, basicamente por três motivos. Primeiro, por ser um procedimento relativamente novo; segundo, por ser uma técnica não disciplinada por Lei em alguns países; e terceiro, porque a verdade consensual se opõe à verdade processual, consistindo em uma escolha das partes, sem a figura do juiz.

Prosseguindo neste raciocínio, em segundo lugar tem-se a questão propriamente sociocultural - esta sim, tema primordial do presente trabalho, uma vez que as práticas consensuais têm esbarrado em uma sociedade extremamente litigiosa, desacreditada da capacidade de compor seus conflitos e solucioná-los de forma amigável.

Rodolfo de Camargo Mancuso ${ }^{31}$ leciona que o aumento pela demanda judicial não significa que ela apresenta um desempenho satisfatório, mas pelo contrário, somente

\footnotetext{
${ }^{30}$ MORAIS, José Luiz Bolzan de; SPENGLER, Fabiana Marion. Mediação e arbitragem: alternativas à jurisdição! 3. ed. Porto Alegre: Livraria do Advogado, 2012.

${ }^{31}$ MANCUSO, Rodolfo de Camargo. Acesso à justiça: condicionantes legítimas e ilegítimas. São Paulo: Revista dos Tribunais, 2011.
} 
Revista Eletrônica de Direito Processual - REDP.

Rio de Janeiro. Ano 15. Volume 22. Número 1. Janeiro a Abril de 2021

Periódico Quadrimestral da Pós-Graduação Stricto Sensu em Direito Processual da UERJ

Patrono: José Carlos Barbosa Moreira (in mem.). ISSN 1982-7636. pp. 01-28

www.redp.uerj.br

confirma a existência da cultura da sentença, conforme afirmou Kazuo Watanabe, desestimulando às partes da busca pelos meios alternativos.

Justamente a convivência de pessoas com identidades divergentes que provoca a ocorrência dos conflitos, na medida em que a existência de culturas diferentes acarreta compreensões sobre a realidade e sobre determinados fatos diversas, que raramente são tratadas através do diálogo, razão pela qual acabam dando azo a instauração de processos judiciais.

Esta é a questão central para a efetivação das soluções consensuais dos litígios, ante a problemática cultural a que está inserida a sociedade brasileira, pois o que se verifica são indivíduos extremamente litigantes e que veem no Judiciário a única possibilidade de solução dos seus conflitos, ajuizando ações litigiosas que arrastam-se por longos anos, a fim de se chegar a um mero pronunciamento judicial sobre o mérito, o que nem sempre ocorre, considerando que há todo um formalismo processual que deve ser observado.

Além disso, é preciso enfrentar as desgastantes e não menos morosas fases recursais e executória, até que se chegue (ou não) a satisfação da pretensão. Ocorre que durante este período, o conflito já se desenvolveu de forma tão complexa que se tornou algo muito maior, envolvendo, não raras vezes, ainda mais processos judiciais, contribuindo cada vez mais para o acirramento dos ânimos entre as partes.

Luiz Guilherme Marinoni ${ }^{32}$ afirma que o Poder Judiciário é organizado de acordo com a ideologia dominante, não podendo se afirmar que a justiça é boa ou má, efetiva ou inefetiva, mas, sim, que é de acordo com o que dela se deseja.

Portanto, é necessário que os envolvidos trabalhem a sua capacidade autocompositiva e dialoguem entre si na tentativa de buscar a solução mais adequada e consensual. Tal fato, somente se torna possível com a implementação de uma política pública capaz de despertar na personalidade de cada indivíduo o entendimento dos benefícios e a busca pelo tratamento dos conflitos de forma consensual, e até mesmo extrajudicial, percebendo que, como personagens principais do litígio, têm a plena capacidade de por si só, e de forma dialogada, alcançarem este desiderato, o que somente se torna possível através de uma modificação sociocultural profunda.

\footnotetext{
${ }^{32}$ MARINONI, Luiz Guilherme. Tutela antecipatória e julgamento antecipado: parte incontroversa da demanda. 5. ed. São Paulo: Editora Revista dos Tribunais, 2003.
} 
Ainda que se afirme que o traço cultural de um povo não possa ser modificado, o seu comportamento não pode ser visto como algo irreversível ou imutável. Para isso, é necessário que a própria sociedade perceba através da divulgação de dados objetivos que aqueles comportamentos antes adotados encontram-se ultrapassados e, a partir disso, adote novas posturas ${ }^{33}$.

Para que se chegue ao máximo de perfectibilização da aplicabilidade dos métodos autocompositivos, entende-se que a modificação sociocultural deve ser ainda mais profunda, de modo a interferir na própria concepção humana intrínseca sobre o conflito, o que somente se mostra possível de ser alcançado se for aplicado desde as primeiras interações humanas fora do núcleo familiar, ou seja, nas séries iniciais escolares.

Para Luis Alberto Warat ${ }^{34}$, a mediação nas escolas funciona como a mediação comunitária, e é chamada de paritária. São os próprios alunos que atuam como mediadores para resolver os conflitos criados naquele ambiente, sendo necessário, no entanto, uma capacitação mínima para que possam pôr em prática estas técnicas.

A educação é primordial para a formação de qualquer ser humano, não só no sentido de ensinar disciplinas que qualificam e preparam o indivíduo para a vida, mas também por contribuir fundamentalmente com a formação da personalidade dos sujeitos.

Por isso, entende-se que a escola é o ambiente mais adequado para se efetivar a aplicação de uma política pública de grande abrangência e de efetivo impacto social, que possa modificar a compreensão individual sobre o conflito ainda durante o período primordial de formação da personalidade.

Assim é que se propõe com o presente trabalho que a efetivação da cultura dos métodos consensuais de solução dos conflitos se dê através de uma política pública que possibilite a sua implementação desde as séries iniciais escolares, tratando-se desde cedo os mais diversos tipos de litígios, dos mais simples aos mais complexos, de modo a imbuir e fazer nascer a personalidade pacificadora em cada indivíduo.

Com isso, a longo prazo será possível se verificar a formação de indivíduos que primarão pelo tratamento de seus conflitos de forma adequada, consensual e dialogada,

\footnotetext{
${ }^{33}$ MANCUSO, Rodolfo de Camargo. Acesso à justiça: condicionantes legítimas e ilegítimas. São Paulo: Revista dos Tribunais, 2011.

${ }^{34}$ WARAT, Luis Alberto. Em nome do acordo: a mediação no direito. Rio de Janeiro: Almed, 1999.
} 
sendo possível o estímulo da mesma prática para seus descendentes desde a educação e interação ainda no seio familiar.

Nesse sentido, Roberto Ferrari de Ulhoa Cintra $^{35}$ apresenta a sua "Pirâmide para a resolução de conflitos", com doze fases, tendo por base as duas primeiras como "intimidade do cidadão" e "núcleo familiar", desenvolvendo-se a partir de então as demais etapas, de modo que somente nas quatro últimas etapas se chega ao judiciário, contando ainda, com todo o procedimento de tentativa de composição na esfera judicial. O ideal do autor na obra, é que os conflitos sejam coados a cada degrau da pirâmide, chegando-se ao ajuizamento de ações apenas o residual.

Entrementes, não é caso para a regulamentação por meio de atos legislativos, mas sim pela sensibilidade da criação de uma política pública governamental, tendo em vista que concede maior flexibilidade, sendo possível acompanhar os resultados de maneira mais precisa e delinear eventuais mudanças estratégicas nos métodos empregados para a perfectibilização do objetivo fundamental do programa, o que não seria factível no caso de uma regulamentação legal, por se estar preso a formalismos e preciosismos legislativos.

Isso porque a política pública consiste em um conjunto de ações, programas e decisões adotadas por um governo, com a finalidade de garantir direitos assegurados constitucionalmente aos seus cidadãos, podendo contar ainda com a participação de entes públicos ou privados, seja direta ou indiretamente.

Desta forma, na prática, a ideia da política pública sugerida se daria através de uma disciplina específica que abordaria a temática e criaria atividades reais a serem desenvolvidas, sendo analisado entre os alunos a evolução no dia a dia, a fim de se verificar a sua aprovação na matéria.

O objetivo é que o projeto seja implementado nas turmas iniciais, no primeiro ano do ensino fundamental, prosseguindo para a série seguinte no próximo ano letivo, acompanhando gradativamente a evolução destas turmas inaugurais do programa, sem perder de vista a continuidade da sua implementação nas novas turmas anualmente, até que se alcance o integral ciclo escolar ao chegar no ensino médio.

Para tanto, durante o período, a capacitação dos alunos e professores deve ocorrer por meio de seminários, palestras, reuniões e rodas de conversas, possibilitando a

\footnotetext{
${ }^{35}$ CINTRA, Roberto Ferrari de Ulhoa. A pirâmide da solução de conflitos. Brasília: Senado Federal, 2008.
} 
Revista Eletrônica de Direito Processual - REDP.

Rio de Janeiro. Ano 15. Volume 22. Número 1. Janeiro a Abril de 2021

Periódico Quadrimestral da Pós-Graduação Stricto Sensu em Direito Processual da UERJ

Patrono: José Carlos Barbosa Moreira (in mem.). ISSN 1982-7636. pp. 01-28

www.redp.uerj.br

aplicabilidade fática dos institutos, seja a mediação, conciliação, arbitragem, negociação, ou qualquer outro, diariamente nas relações interpessoais, seja com o auxílio de professores ou por conta própria.

Com efeito, o Ministério Público do Rio Grande do Sul já vem desenvolvendo desde o ano de 2017 o projeto "Pacificação nas Escolas: um olhar restaurativo do MPRS", que embora trabalhe mais com a questão da justiça restaurativa, voltado para reuniões e encontros de formação com os educadores, vê, assim como nós, que a mudança desta personalidade litigante deve ser feita ainda nas escolas, quando se iniciam os primeiros conflitos, contemporaneamente ao passo em que se desenvolvem as características personalíssimas mais fortes do indivíduo.

Deste modo, não há momento melhor para agir e estimular a capacidade cooperativa e autocompositiva dos indivíduos que a escola, porquanto é o momento oportuno para demonstrar à eles, ainda neste ambiente, em seus primeiros momentos de interação com terceiros, que todos os seus desentendimentos são passíveis de serem tratados de forma dialogada.

A mediação para tratar conflitos ainda nas escolas é o melhor caminho a ser tomado, uma vez que estabelece o resgate de valores e respeito perante os envolvidos, tornando o conflito uma forma de transformação dos indivíduos, a fim de que percebam que é possível resolver seus litígios a partir do diálogo e da educação ${ }^{36}$.

Além disso, a prática poderá ser estimulada com o auxílio/intermédio dos professores, que atuarão como mediadores/conciliadores no caso concreto, caso seja necessário, sendo indispensável que para tanto, os educadores contem com um estímulo e formação inicial básica nesta prática.

Veja-se, neste sentido, que o papel do mediador nas escolas é muito importante, tendo em vista que facilita a comunicação entre os próprios alunos, com o professor ou direção. Aqui, o objetivo principal é tratar o conflito a partir dos problemas por ele criados (briga, discussão ou violência), buscando encontrar motivos para explicar o conflito, as possíveis soluções e, por fim, o que pode ser feito para evitar a sua nova ocorrência.

36 OLIVEIRA, Júlia Francieli Neves de; MARCO, Thaís Kerber De. Mediação de conflitos: instituto democrático-dialógico de exercício de cidadania na construção de soluções satisfatórias nos conflitos escolares. 2013. Disponível em: http://coral.ufsm.br/educomsul/2013/com/gt1/11.pdf. Acesso em: 18 mai.2019. 
Revista Eletrônica de Direito Processual - REDP.

Rio de Janeiro. Ano 15. Volume 22. Número 1. Janeiro a Abril de 2021

Periódico Quadrimestral da Pós-Graduação Stricto Sensu em Direito Processual da UERJ

Patrono: José Carlos Barbosa Moreira (in mem.). ISSN 1982-7636. pp. 01-28

www.redp.uerj.br

Todavia, adverte-se que para que se alcancem os ideais e os objetivos que se almejam com esta prática, se torna imprescindível deixar de lado o preciosismo e o formalismo para a sua consecução, tendo em vista que deve ser aplicada de forma natural, quase que imperceptível aos olhos dos participantes, até mesmo em razão do público alvo, que são crianças em fase inicial de desenvolvimento. Da mesma forma, é preciso se desligar do imediatismo, outra típica característica brasileira, considerando que um projeto com este objetivo se destina primordialmente a produzir efeitos futuros, sendo necessário persistir e acreditar para colher os seus frutos.

Por tudo isso, tem-se que diante do cenário em que se encontra o Poder Judiciário nacional, somente uma política pública desta natureza será capaz de mudar esta realidade social, pois como já insistentemente mencionado se trata de um problema sociocultural, não havendo alternativa para fugir desta crise iminente que não com um profundo combate essencial às suas causas.

\section{CONCLUSÃO}

A partir do estudo realizado, evidencia-se que o direito fundamental do acesso à justiça previsto constitucionalmente não é, e nem pode ser, o mero direito de ação, de simplesmente levar até o Poder Judiciário o conflito existente. $\mathrm{O}$ acesso à justiça deve ser visto primordialmente como o direito à uma ordem jurídica justa, que por sua vez, significa a possibilidade de as partes chegarem a verdadeira solução do seu conflito, tanto pessoal como jurídico, de forma tempestiva, em período razoável de duração do processo.

Entretanto, o que se nota na atualidade é que o sistema judiciário como um todo não acompanhou a evolução das relações humanas, que ao longo dos anos se modificaram e se tornaram mais complexas, possibilitando aos litigantes acessá-lo, como não poderia deixar de ser, mas não lhes garantindo a efetiva ordem jurídica justa, pois não deu conta da quantidade estrondosa de conflitos que chegaram até o Judiciário nas últimas décadas, ocasionando a crise que hoje assola este Poder.

Desse modo, passou-se ao resgate e positivação dos métodos consensuais de resolução dos conflitos pelo legislador, tanto auto como heterocompostivos, criando-se novos diplomas legais para regulamentar a aplicação dos institutos de forma judicial e 
Revista Eletrônica de Direito Processual - REDP.

Rio de Janeiro. Ano 15. Volume 22. Número 1. Janeiro a Abril de 2021

Periódico Quadrimestral da Pós-Graduação Stricto Sensu em Direito Processual da UERJ

Patrono: José Carlos Barbosa Moreira (in mem.). ISSN 1982-7636. pp. 01-28

www.redp.uerj.br

extrajudicial, com o nítido objetivo de se combater o crescente aumento no número de ações judiciais.

Todavia, o que se buscou demonstrar com o presente estudo é que mesmo após a criação e regulamentação dos meios autocompositivos para o tratamento de conflitos, que possuem comprovados efeitos positivos para a sociedade e às próprias partes, não se alcançaram os resultados esperados, permanecendo o aumento crescente no número de demandas.

Isso porque, além de contar com poucos recursos e com a demora para a regulamentação definitiva dos institutos, o projeto esbarrou em uma sociedade fundamentalmente litigante, que prima pelo tratamento de seus conflitos principalmente pela via judicial, acreditando que somente através de um pronunciamento judicial se chegará à "solução" do desentendimento travado, adjudicando ao Estado-juiz o dever de "resolver o conflito", afirmar quem tem ou não tem razão, nem que para isso tenham de enfrentar o custoso e moroso processo judicial, abdicando da capacidade de que, por si próprios, cheguem até o entendimento através do diálogo.

Por tudo isso, chegou-se à conclusão de que se trata de um problema inerentemente sociocultural, de modo que somente uma estratégia capaz de alterar esta realidade litigiosa dos indivíduos é que poderá surtir os efeitos que se espera, o que no nosso sentir deve ocorrer ainda durante a infância, quando se desenvolvem as características personalíssimas dos indivíduos.

Nesse sentido, propôs-se a criação de uma política pública para instituir ainda nas séries iniciais escolares o estímulo ao tratamento consensual e dialogado dos conflitos, especialmente por se tratarem das primeiras interações humanas com terceiros, fora do ambiente familiar, local em que começam a se desenvolver os primeiros conflitos cotidianos. Desta forma se possibilitaria aos infantes tratar de forma dialogada e consensual os seus desentendimentos, por mais irrelevantes que pudessem aparentar, a fim de verdadeiramente criar uma cultura de resolução de conflitos voltada para a paz, na medida em que crescerão, e como adultos levarão estes ensinamentos para qualquer litígio que virem a enfrentar.

Na prática, entende-se que isto deva ocorrer através de uma política pública dirigida às escolas, com uma capacitação básica dos educadores, bem como com a criação de uma 
disciplina específica, na qual os alunos serão orientados por meio de rodas de conversas, seminários, e avaliados constantemente durante o período letivo, verificando a sua evolução para fins de aprovação na matéria.

Com isso, diante da atual crise do sistema judiciário tradicional, verifica-se que somente com uma estratégia de mudança sociocultural será possível alterar esta realidade. A simples regulamentação dos métodos e a sua quase que obrigatoriedade, por mais louváveis que sejam os seus objetivos, não são suficientes para promover a diminuição da carga de processos judiciais que existem no Brasil.

Assim, não podemos nos apegar em um raciocínio imediatista. É necessário sim promover e incentivar a aplicação dos métodos consensuais no presente, entretanto, é ainda mais importante se olhar para o futuro e perceber a necessidade de promover uma mudança de comportamentos, para que mais adiante não se chegue a um colapso total.

\section{REFERÊNCIAS}

BRASIL. Constituição da República Federativa do Brasil. Brasília, DF: 1988. Disponível em: http://www.planalto.gov.br/ccivil_03/constituicao/constituicao.htm. Acesso em: 22 mai.2019.

BRASIL. Lei n. ${ }^{\circ}$ 13.140, de 26 de junho de 2015: dispõe sobre a mediação entre particulares como meio de solução de controvérsias e sobre a autocomposição de conflitos no âmbito da administração pública; altera a Lei no 9.469, de 10 de julho de 1997, e o Decreto $\mathrm{n}^{\circ} 70.235$, de 6 de março de 1972 ; e revoga o $\S 2^{\circ}$ do art. $6^{\circ}$ da Lei no 9.469, de 10 de julho de 1997. Brasília: Senado Federal, 2015. Disponível em: http://www.planalto.gov.br/ccivil_03/_Ato2015-2018/2015/Lei/L13140.htm. Acesso em: 15 abr.2019.

BRASIL. Lei n. 13.105, de 16 de março de 2015: Código de Processo Civil. Brasília: Senado Federal, 2015. Disponível em: http://www.planalto.gov.br/ccivil_03/_Ato2015-2018/2015/Lei/L13105.htm. Acesso em: 29 mar.2019. 
BRASIL. Lei n. ${ }^{\circ}$ 9.307, de 23 de setembro de 1996. Dispõe sobre a arbitragem. Brasília, DF: Senado $\quad$ Federal, $1996 . \quad$ Disponível em: http://www.planalto.gov.br/ccivil_03/leis/19307.htm. Acesso em: 08 jun.2019.

BRASIL. Manual de mediação judicial do Conselho Nacional de Justiça. Brasília: 2016. http://www.cnj.jus.br/files/conteudo/arquivo/2016/07/f247f5ce60df2774c59d6e2ddd bfec54.pdf. Acesso em: 13 de mai.2019.

BRASIL. Conselho Nacional de Justiça. Resolução n. 125, de 29 de novembro de 2010. Política Judiciária Nacional de tratamento adequado dos conflitos de interesses no âmbito do Poder Judiciário. Brasília: Conselho Nacional de Justiça, 2010. Disponível em: http://www.cnj.jus.br/busca-atos-adm?documento=2579. Acesso em: 29 abr.2019.

BRASIL. Conselho Nacional de Justiça. Justiça em números. Disponível em: http://www.cnj.jus.br/files/conteudo/arquivo/2018/09/da64a36ddee693ddf735b9ec03 319e84.pdf. Acesso em: 14 mai.2019.

CAPPELLETTI, Mauro; GARTH, Bryant. Acesso à justiça. Porto Alegre: Safe, 1988.

CINTRA, Roberto Ferrari de Ulhoa. A pirâmide da solução de conflitos. Brasília: Senado Federal, 2008.

GORCZEVSKI, Clóvis. Jurisdição paraestatal: solução de conflitos com respeito à cidadania e aos direitos humanos na sociedade cultural. Porto Alegre: Imprensa Livre, 2007.

HABERMAS, Jurgen. Teoria de la acción comunicativa, I: racionalidad de La acción y racionalización social. Madrid: Taurus, 1987.

MANCUSO, Rodolfo de Camargo. Acesso à justiça: condicionantes legítimas e ilegítimas. São Paulo: Revista dos Tribunais, 2011.

MARINONI, Luiz Guilherme. Política pública do Poder Judiciário nacional para tratamento adequado dos conflitos de interesses. Revista de Processo, São Paulo, n. 195, mai. 2011.

MARINONI, Luiz Guilherme. Tutela antecipatória e julgamento antecipado: parte incontroversa da demanda. 5. ed. São Paulo: Editora Revista dos Tribunais, 2003. 
MORAIS, José Luiz Bolzan de; SPENGLER, Fabiana Marion. Mediação e arbitragem: alternativas à jurisdição! 3. ed. Porto Alegre: Livraria do Advogado, 2012.

NALINI, José Renato. A rebelião da toga. Campinas: Millenium, 2006.

OLIVEIRA, Júlia Francieli Neves de; MARCO, Thaís Kerber De. Mediação de conflitos: instituto democrático-dialógico de exercício de cidadania na construção de soluções satisfatórias nos conflitos escolares. 2013. Disponível em: http://coral.ufsm.br/educomsul/2013/com/gt1/11.pdf. Acesso em: 18 mai.2019.

PAROSKI, Mauro Vasni. Direitos fundamentais e acesso à justiça na Constituição. São Paulo: LTr, 2008.

SPENGLER, Fabiana Marion. Da jurisdição à mediação: por uma outra cultura no tratamento dos conflitos. Ijuí: Unijuí, 2010.

TARTUCE, Fernanda. O novo marco legal da mediação no direito brasileiro. 2016. Disponível em: http://www.fernandatartuce.com.br/wp-content/uploads/2017/01/Onovo-marco-legal-da-mediacao-no-direito-brasileiro-2016-Fernanda-Tartuce.pdf. Acesso em: 18 mai.2019.

TARTUCE, Fernanda; SILVA, Erica Barbosa. A conciliação diante da política judiciária de tratamento adequado de conflitos. In TUCCI, José Rogério Cruz; RODRIGUES, Walter Piva; AMADEO, Rodolfo da Costa Manso Real (Coord.). Processo civil: homenagem a José Ignacio Botelho De Mesquita. São Paulo: Quartier Latin, 2013.

VEZZULA, Juan Carlos. A mediação de conflitos com adolescentes autores de ato infracional. Florianópolis: Habitus, 2006.

WARAT, Luis Alberto. A mediação. 1999. Disponível em: http://www.almed.org.br. Acesso em: 29 mai.2018.

WARAT, Luis Alberto. Em nome do acordo: a mediação no direito. Rio de Janeiro: Almed, 1999.

WARAT, Luis Alberto. O ofício do mediador. Florianópolis: Habitus, 2001.

WATANABE, Kazuo. Acesso à justiça e sociedade moderna: participação e processo. São Paulo: Revista dos Tribunais, 1988.

WATANaBe, Kazuo. Política pública do Poder Judiciário nacional para tratamento adequado dos conflitos de interesses. [S.1.]: Virtual Books, 2011. Disponível em: http://www.tjsp.jus.br. Acesso em: 23 mai.2019. 